\title{
Applying Turner's Three-Process Theory of Power to the Study of Power Relations in a Troubled Information Systems Implementation
}

\author{
Michelle Yaqian Ye \\ University of Tasmania \\ yaqian.ye@utas.edu.au \\ Kristy de Salas \\ University of Tasmania \\ Nadia Ollington \\ University of Tasmania \\ Judy McKay \\ Swinburne University of Technology
}

\section{Abstract}

This paper explores the nature and exercise of power in an interpretive case study of a troubled information systems (IS) implementation in a university in the Asia Pacific region using Turner's Three-Process Theory of Power based on Social Identity Theory and SelfCategorisation Theory. The findings demonstrate the value of Turner's theoretical lens as well as its insufficiency for explaining all power related activities. This research has led to the development of an extended Three-Process Theory of Power by adding the alternative components that emerged from the data in the case study in relation to the nature and exercises of power. Based on the findings, we further recommend specific guidelines for IS theoreticians and practitioners including advice to project managers on a range of key issues. Thus, this paper contributes theorising the sources of power and tactical applications of power in given situations, particularly in IS implementation projects.

Keywords: Power; power relations; IT project; IS implementation; resistance; social identity; psychological group

\section{Introduction}

Information systems (IS) project management has been seen as a challenging task, with critical reasons for failure including a lack of top management engagement and support, a weak project champion, inadequate information requirements determination, communication issues, organisational politics, lack of user involvement and participation, and change management problems generally (Flowers 1997; Kappelman, McKeeman and Zhang 2006; Oz and Sosik 2000). Given that political issues are among the critical causes of failure of IS implementation projects (Kappelman et al. 2006; Oz and Sosik 2000), power and how it is exercised are important factors in successful IS projects (Jasperson et al. 2002). IS implementation projects redistribute information and power in organisations, and thus power relations are implicated in such projects and affect both project progress and ultimately project success (Backhouse, Hsu and Silva 2006; Silva and Fulk 2012). The effective and ethical use of power may be necessary in order to achieve innovation and change through IS implementation projects (Ngwenyama and Nielsen 2014). Indeed, while 'power over' may imply domination and bullying (Clegg 1989; Dahl 1957), 'power to' may imply the need to exercise power in order to get things done (Gohler 2009).

Past research on power in IS implementation mainly focuses on the relations between project stakeholder groups, such as between project practitioners and system users (Doolin 2004; Kerr, Houghton and Burgess 2007; Silva and Backhouse 2003). Existing research lacks a real analysis of power relations between project team members (Hussain and Cornelius 2009; Silva and Fulk 2012), which is argued to be an important facet of power relations. More recently, 
Chang and Yeh (2014) argued that the relationships between intra-project team disagreements and conflict communications are important factors for project performance and decisionmaking. Therefore, we attempt to gain a deeper understanding of power relations within an IS implementation by including the analysis of intra-project team power relations, which would fill a void existing within the current research literature.

Most IS literature on power in IS implementation is focused on the work of social and political theorists, in particular, Clegg (Silva 2007; Silva and Backhouse 2003; Smith et al. 2010), Giddens (Brooks 1997; Chu and Smithson 2007; Hussain and Cornelius 2009), Foucault (Doolin 2004; Knights and Vurdudakis 1994), Lukes (Howcroft and Light 2006; Markus and Bjorn-Andersen 1987) and Latour (Bloomfield et al. 1997). The work of these theorists is argued to be abstract and fails to deliver a clear and useful picture regarding the source of power and tactical applications of power in given situations (Ye et al. 2014), and as such, the analyses based on these works offer little practical guidance regarding the effective management of power in IS implementation. Although there are publications by academics in the IS field that contribute a pragmatic and tactical analysis of power relations in IS implementation (Mathiassen and Napier 2014; Sabherwal and Grover 2010), these contributions lack a theoretical grounding to underpin the behaviours they describe. The current paper aims to improve this situation by applying a social psychological theory which provides researchers with a basis for theoretically informed yet practical research in power relations in IS implementation, namely, Turner's (2005) Three-Process Theory (TPT) of Power. Further, the current study identifies the ways in which the theory can be contextualised and/or extended and thus leads to a possible reconceptualisation of the boundaries in which the theory helps to explain the investigated phenomena. There are two overarching research questions (RQs):

\section{RQ1: What power relations can be identified within an IS implementation project?}

RQ2: Does TPT provide a useful theoretical lens for understanding the interplay of power relations within an IS implementation project?

In the remainder of the paper, we provide: (1) a summary and explanation of the key propositions of Turner's TPT and its associated underpinning theories of Social Identity Theory (SIT) and Self-Categorisation Theory (SCT); (2) the methodology, explaining the research context, data collection and analysis; (3) the findings, comprising the final themes and codes, their relationships to the TPT propositions, and the proposed extension to the TPT with the alternative components that emerged from the data; (4) the discussion, concluding the findings and answers to the RQs; and finally (5) the conclusion, providing insights for project managers or system implementers and discussing future research directions.

\section{Propositions of Turner's Three-Process Theory of Power}

Turner's TPT has a firm theoretical and empirical basis in SIT and SCT (Tajfel and Turner 1979; Turner et al. 1987). SIT was developed to explain the psychological basis of intergroup behaviours, particularly the discrimination of in-group members against out-group members (i.e. 'us' versus 'them') (Hogg and Turner 1985). SCT argues that individuals have a rough hierarchy of categories or identities that they refer to in their social life, and belonging to a particular category is equivalent to belonging to a psychological group in which a series of values and interpretations are shared (Hornsey 2008; Turner 1991). The acceptance of a category or an identity may occur over a long period of time, but can at times occur quickly in a particular situation. Thus based on SIT and SCT, Turner (2005) introduces the concept of psychological group formation for describing the nature or source of power (see Figure 1). 


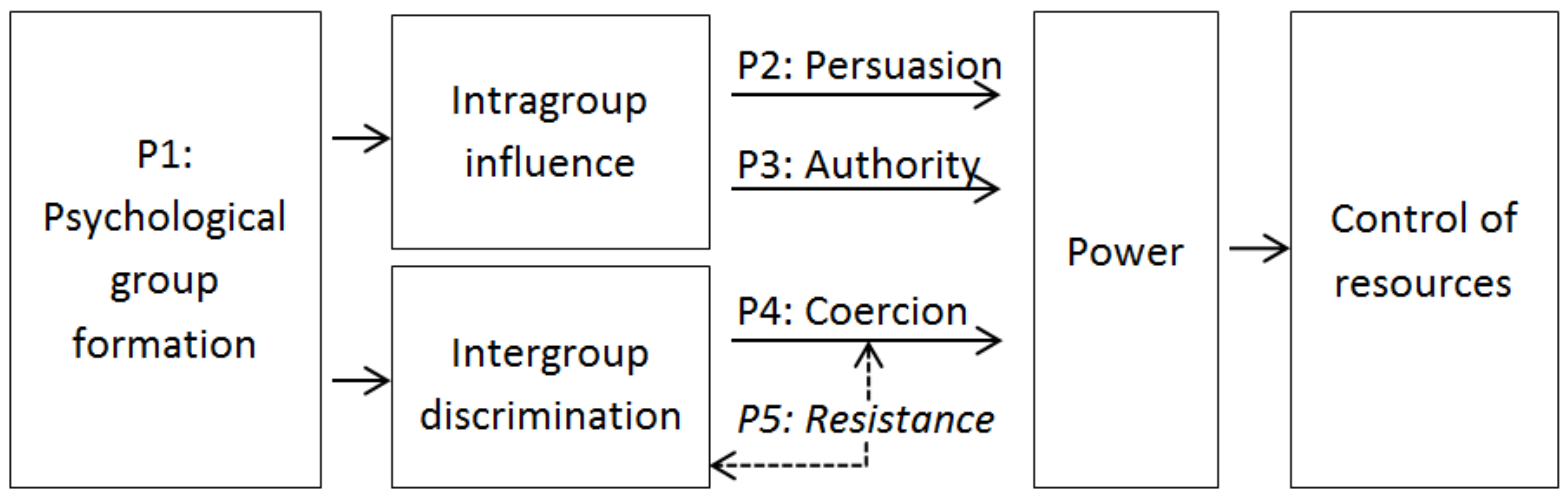

Figure 1. The Three-Process Theory of Power (Adapted from Turner (2005)).

Based on the above concept, Turner (2005) argues that psychological group formation produces influence which gives people power through the processes of persuasion, authority, and coercion. Turner also suggests that in turn, power leads to the creation and control of resources. It is argued that power is not grounded in material resources but it is group identity that confers power. The five propositions of Turner's theory are discussed below.

\section{Proposition 1 - People tend to self-categorise into psychological group(s) and these self-categorisations become relevant in determining behaviours in particular contexts or situations.}

An example of such categories may be those categories applying to two female academics, one an accounting academic and the other a management academic, both in University X. These two persons would likely belong to such groups as University $\mathrm{X}$, the Business School of University X, academics, and women; these groups being in a rough and perhaps overlapping hierarchy. In a faculty budget situation, these two women may be rivals and power players in the competition for resources, but in a different situation, may both support the University in building its reputation in competition with other universities. At an even more inclusive level, both academics may support women in general in equal pay and other social justice issues. Thus, different categories have salience in different situations.

\section{Proposition 2 - Psychological group formation produces a situation of mutual influence through a shared identity, which forms the basis of power through persuasion.}

People in a psychological group perceive themselves as more similar to each other than they are with people in a different group, and therefore they expect to have similar views within their psychological group. People are more likely to be persuaded by intragroup members as they usually have shared attitudes, beliefs and experiences. This forms the basis for intragroup influence, and promotes the exercise of power through persuasion (Turner 1987).

For example, Andrew and Michael are two members of Y Team in the X Project Team, where Andrew is the Y Team Leader and Michael is a Y Team worker. When Michael's identity as a member of Y Team becomes salient and the matter of discussion is about the improvement of their team performance, Andrew tends to be perceived by Michael as an in-group member based on the shared identity, and thus they tend to engage in mutual persuasion to reach agreement. The shared group identity unifies and empowers Andrew and Michael by encouraging in-group consensual support. Intragroup similarities between Andrew and Michael are apparent in this context because they are categorically interchangeable as members of Y Team (Oakes, Haslam and Turner 1994; Turner 1984).

\footnotetext{
Proposition 3 - Authority is the power based on in-group norms that group members ought tofollow a specific person or position (leader) who has the right to control them in certain matters.
} 
Authority in TPT is power that is legitimated by in-group norms that have a shared social identity as their basis. It is conferred by "formal agreement, custom or the norms inherent in group activity" (Turner 2005, p. 11), thus facilitating collective action to achieve common goals and quick decisive action at times and in situations where it is necessary. Thus the tacit or formal agreement involved in authority permits a designated group member to control others in the in-group. Authority, then, short-circuits the debates, deliberations, and arguments that may take place without such a working agreement in place.

A typical in-group in which authority commonly operates, is the psychological category or group of committed members of a business or government organisation. In order to retain the group membership and the benefits that flow from being an employee, members of business and government organisations submit voluntarily to the authority hierarchy of the organisation. To take the example further, consider the two members Andrew and Michael of $\mathrm{Y}$ Team in the X Project Team, where Andrew is the Y Team Leader. At the personal level Michael and Andrew may disagree, however if the disagreement is about X Project matters then the authority hierarchy of the organisation becomes salient and Michael is likely to go along with Andrew because Andrew has the authority of a Team Leader. Michael then agrees, not necessarily because he is persuaded, but because he is submitting to the legitimate authority. That is, Michael agrees that Andrew has the authority right conferred by the group norms (team hierarchy) to mandate that to him.

\section{Proposition 4 -Coercion is the power to control a target against their will through the deployment of resources to constrain and manipulate their behaviour.}

Turner (2005, p. 12) refers to coercion as "authority in a dark mirror". It is the form of power employed when one is not able or is not willing to persuade, and when one does not possess legitimate authority. Given this, it is likely that persons resorting to coercion in a given situation may lack a shared identity with the target(s) of the coercion. As such, they may have little basis for persuasion and are perhaps also less likely to possess any legitimate authority in the view of the target(s).

As an example of coercion, consider the example of Michael and Andrew. Y Team Worker, Michael, is told by his Team Leader to work through meal breaks until midnight in order to finish work on a number of important deliverables, but Michael believes Andrew's command to be outside of Andrew's authority. In this context, Andrew may have become a coercive agent of his superior in the X Project Team, at least perceived by Michael.

\section{Proposition 5 - When coercion is perceived to a degree resistance can occur, which leads to a threat to the psychological group identity that people wish to retain.}

In the above example in Proposition 4, the situation was considered overt resistance. However, in the face of threats to fire him, Michael eventually complies. At the same time Michael may take action to quietly resist Andrew's command such as secretly taking meal breaks, and further, now mistrusting Andrew, decide to look for ways to resist future coercion attempts. Thus, the use of coercive power is not without its problems. Coercion tends to generate mistrust in targets, and weakens the possibilities of the future use of persuasion and authority (Kramer 1999). Thus it undermines possibilities for legitimate influence. Further, coercion provokes and encourages resistance and leads to the need for surveillance in order to enforce its conditions (Turner 2005). Thus, a risk of coercion is that it tends to weaken the power of those applying it as it may bring into being an adversary opposed to the source of the coercion. TPT thus includes an explanation of phenomena as resistance (van Dijk and van Dick 2009) and persistence with failing projects (Haslam et al. 2006).

The five propositions articulated above form the basis of Turner's (2005) theoretical lens that guided the current research. The social identity approach (i.e. SIT and SCT) has been shown to have large value for the understanding of power related behaviours in Information Technology (IT) based organisational change (Schwarz and Watson 2005; Tansley, Huang and Foster 
2013), non-IT-based organisational change (Currie, Finn and Martin 2010; van Dijk and van Dick 2009) and in other social science disciplines (Fritsche et al. 2013; Hogg et al. 2005; Hornsey, Blackwood and O'Brien 2005). Based on the firm theoretical foundation of SIT and SCT, Turner's theory appears to be an insightful framework for understanding and interpreting different group members' experiences and perceptions of persuasion, authority, and/or even coercion in project events surrounding the issues and problems inhibiting a project's progress. It enables researchers to draw on particular power-related events in project groups, which are usually constituted by different professional groups/stakeholders, different gender groups, or different hierarchical levels.

\section{Methodology}

This research is an exploratory study. The ontological preference of the current research is for people's perceptions and actions informed by the organisational and social contexts within which they work and live. This ontological view, as explained by Orlikowski and Baroudi (1991), emphasises the subjective meanings that participants assign to the world around them, rather than the objective belief that the social and physical worlds exist independently of the human actors. With reference to this study, a subjective ontology is acknowledged. Holding to the belief that to understand the meaning of the social world one must interpret it (Schwandt 1994), and given the focus of this research being the identification and interpretation of human relational factors affecting an IS implementation project, an interpretivist approach to undertaking the study was adopted.

Based on the subjective ontology and interpretivist epistemology, a longitudinal case study was conducted in a university in the Asia Pacific region over a period of two years (from May 2012 to June 2014). The case study method was adopted as it is particularly well-suited for understanding the interrelationships between IS implementation change and management practices in an organisational context (Benbasat, Goldstein and Mead 1987).

\subsection{Research Context}

The site for this research was a university in the Asia Pacific region, named as AsiaPac University (pseudonym). The focus of analysis in the case study is the power relations and resistance behaviours throughout the implementation of a large student system (SS) that integrates approximately 150 systems covering various business areas, a core business transformation project in AsiaPac University.

The project was initiated in 2006 and eventually went live in 2014 (see Figure 2). Since its first Business Case was approved in 2007, the project was troubled with multiple time and budget overruns. The Business Case was revised twice as was the go-live date. Until the end of our case study in 2014, the project had stalled in the pre-go-live stage of a project lifecycle. Significant project structure changes also occurred, particularly to project leaders. 


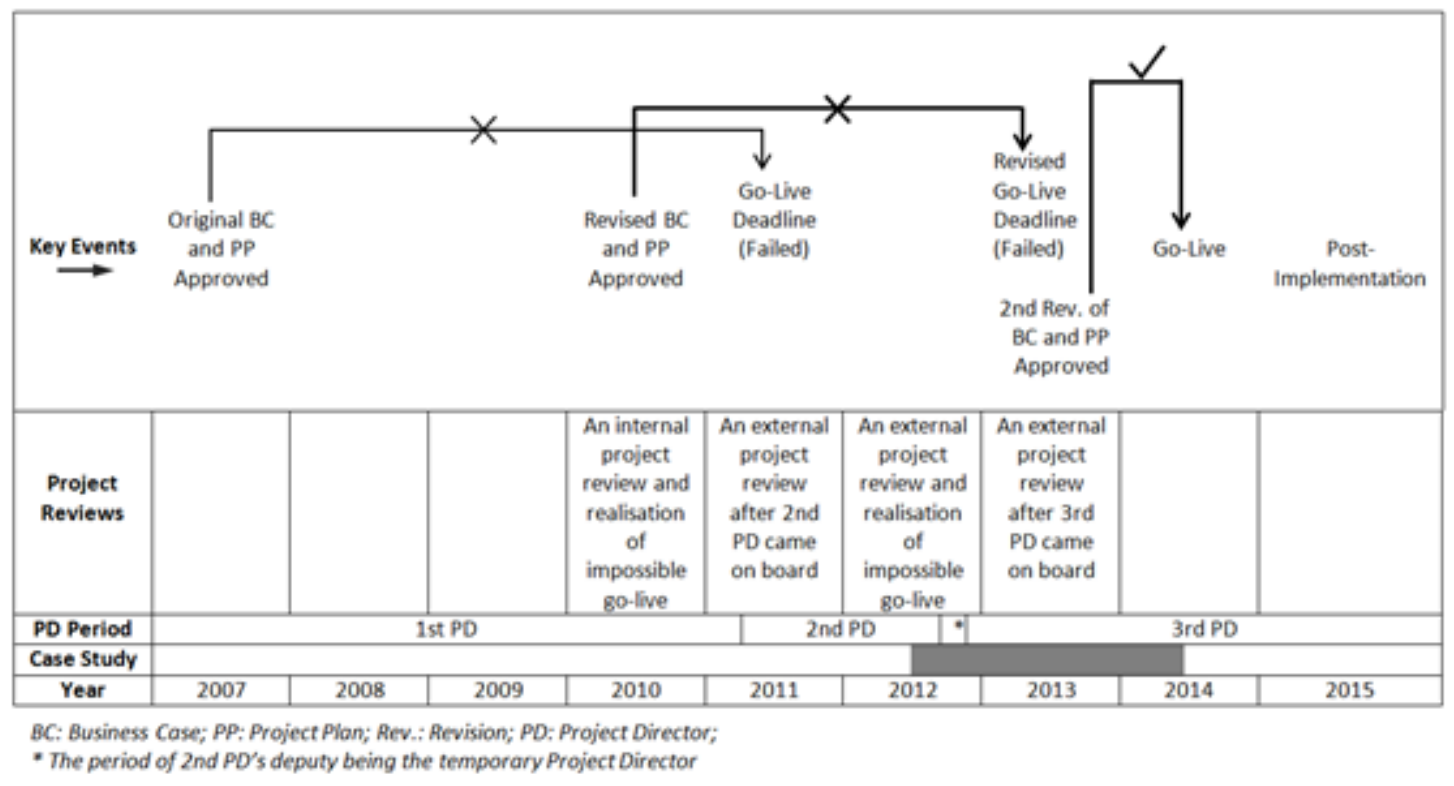

Figure 2. The Timeline of the SS Project.

The SS project was initiated in 2006 with the objective to assess and review options for transforming the university's approach to student and academic administration, and the systems required to support the service delivery. In late 2007, the SS Project Steering Committee endorsed a Business Case and approved the recommended option - to buy a commercially available student information system. The project was allocated a budget of around \$11 million and the go-live date for the SS system was June 2011. A project team of 11 members was assembled.

Early progress was slow and some problems emerged, but it was assumed that the project was progressing reasonably well. Nonetheless with some anxieties voiced, an external review was announced in 2010. This review was highly critical and caused shock waves in the University Council, which reported that given the progress to date, the budget and timeline were insufficient and the project team would not be able to meet the targeted 2011 implementation timeframe. Discussions among Council members and the Vice Chancellor led to the Vice Chancellor replacing the Project Director after 4 years heading up the project team.

The new Project Director was recruited from outside the university, previously the CEO of an online service company, despite having no experience of directing and managing large and complex IS implementation projects. The second Project Director reviewed the original Business Case and had a new Business Case prepared, which was approved in December 2010 with a new timeline, and an increased budget and resources. The new project budget was almost doubled to $\$ 22$ million and the project team was increased to over 30 members. However, the project fared little better under the new Project Director.

The second Project Director had a remote 'CEO style' and did not tend to set clear directions for the project team leaders. His lack of hands-on project management became obvious to a number of senior members of the project team. His upward communications to the senior management team in the university were reassuring and so it was another shock to the Council and Vice Chancellor when a second external review of the project showed it to be in a parlous state, having no chance of meeting the planned go-live date. The second Project Director, seeing the writing on the wall, left the university.

After the second Project Director left, the Project Director's deputy took charge of the SS project with a view to her holding this position until the next Project Director was appointed. The temporary Project Director struggled to give the project team a sense of stability and progress. A number of people in the project team became disillusioned with the lack of direction and progress and left the university. Painfully aware that the project was not making 
progress and bedevilled by a number of fractious disputes within the project team, the temporary Project Director resigned.

In late October 2012, a new Project Director who had experienced complex projects was recruited from outside the university. The new Project Director, needing to accurately and publicly establish the current state of the project, instituted another comprehensive external review of the project and then based on the findings, argued that the April 2013 go-live target was no longer possible. However, the senior management of AsiaPac University was now getting impatient with the retreating go-live dates. Thus the Vice Chancellor brought considerable pressure to bear on the new Project Director, insisting, among other things that she meet the deadline of September 2013 as a compromise of the previous April deadline. This time however, the new Project Director was a professional and highly experienced project manager who could clearly see that the deadline was completely unrealistic and so she refused to commit to it. This caused confrontation between her and the senior management. For a while it seemed that the new Project Director would be dismissed and she walked out of the position in protest to the unrealistic deadline. During this time of uncertainty for the SS project, the Vice Chancellor requested that the University CIO get involved in the project to assess whether the deadline was in fact unattainable as the new Project Director was asserting. The CIO spoke with the project team members and was told quite firmly by a number of them that the new Project Director was correct. The upshot was that the new Project Director was requested to come back to take charge of the project and the University Council was informed that the new Project Director's assessment of July 2014 as an approximate go-live date was now the official target date for the implementation of the new system.

The new Project Director then started detailed work on the new Project Management Plan and the third Business Case based on the revision of timeline, resource and budget at the same time of working with the external review team and re-structuring the project team. By that time, the new project budget was almost doubled again to $\$ 40$ million and the size of the project team was significantly increased to over 60 members. The SS project then began to move in the right direction under the third Project Director's leadership and finally went live within the designated timeline.

\subsection{Data Collection and Analysis}

The data collection and analysis process involved two phases as shown in Figure 3, during which a series of interviews were conducted (18 and 30 respectively). In the first phase, the matters of power relations, politics, and group influence emerged from the initial data collection. In the second phase, noting the emergence of aspects of Turner's theory from the preliminary analysis, a more focused, theoretically informed approach was conducted in which Turner's theory was used a lens to guide subsequent data collection and analysis. 


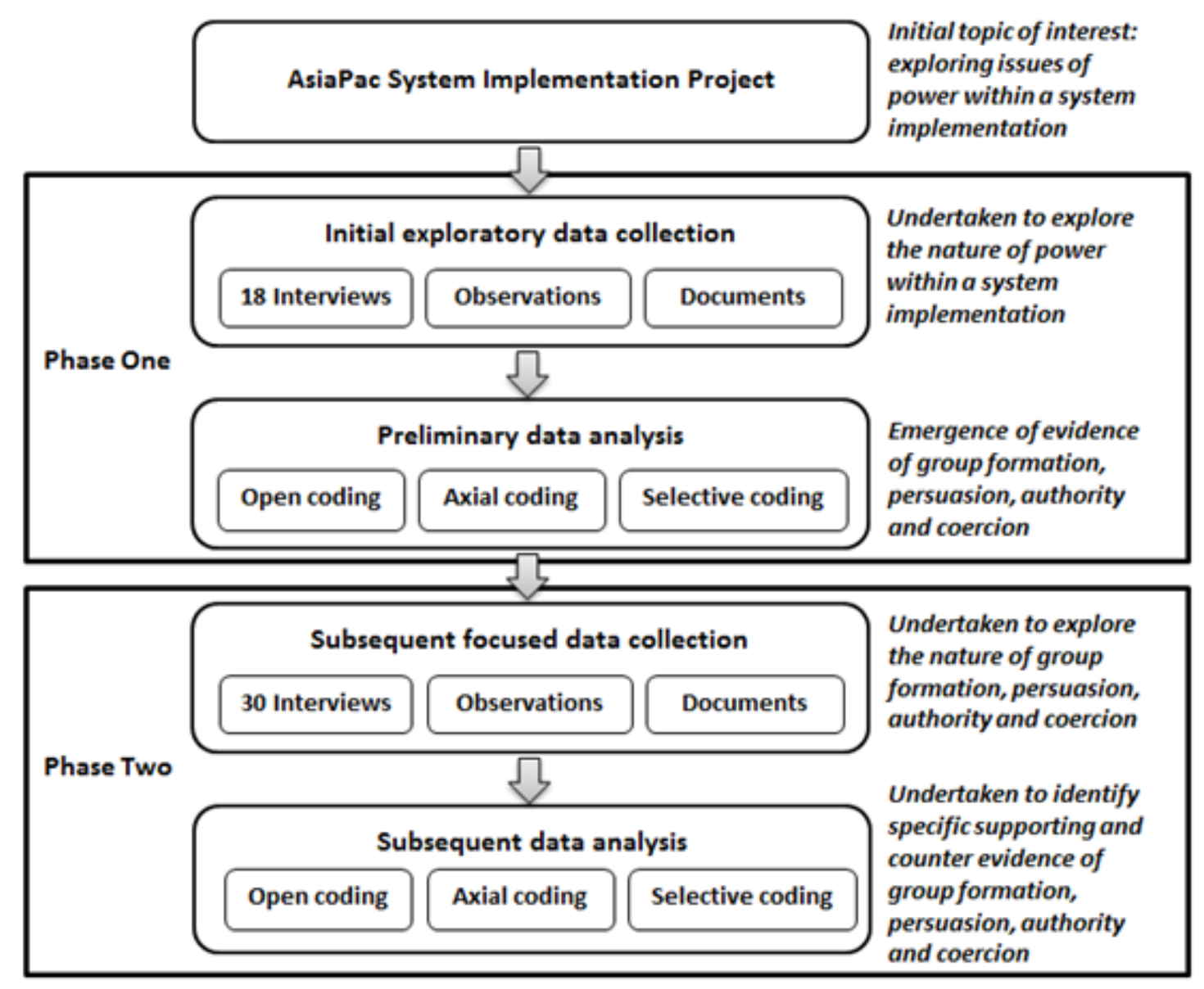

Figure 3. Data Collection and Analysis Process.

In both phases, data was collected by:

1 Forty-eight in-depth, open-ended interviews of between 50-90 minutes with 46 participants (see Table 1), among whom two were heavily involved project leaders, and as such were interviewed twice for further in-depth conversation. The interviews were delivered face-to-face, except for one telephone interview. Each of the 47 face-to-face interviews was recorded by using a digital audio voice recorder, and written-notes were taken during the telephone interview. At the beginning of each interview, key concepts were explained by the researcher and a few general questions were asked to elicit conversation. The researcher used improvisation strategies, and listening strategies as suggested by Myers and Newman (2007), in order to construct questions or provide prompts based on the participant's response.

2 Non-participant observations in ten project meetings, three user workshop sessions and informal discussions with participants. The observations were written within the field notes, which also included a reflective diary and a factual event listing in order to provide additional assistance in contextualising and interpreting the data.

3 Study and analysis of the project related documents. Primary documentation was provided by project managers including Project Plans, Business Cases, Project Team Structure diagrams, meeting agendas and meeting minutes. Secondary documentation was obtained from the publicly available resources on the organisational website including the monthly issues, presentations and demonstrations for users and project news.

Interviews were the primary source of data, with the other two sources used to contextualise and confirm the researchers' understanding of data throughout the analysis phase. The 
recordings from the interviews were transcribed line by line together with written notes being read through in order to understand the participants' interpretations of events.

\begin{tabular}{|c|c|}
\hline Inside the Project Team & Outside the Project Team \\
\hline $\begin{array}{l}\text { Project Leaders (PL1-5) } \\
\text { (Project Managers/Directors, } \\
\text { Assistant/Deputy Project Directors) }\end{array}$ & $\begin{array}{l}\text { Senior Management (SM1-5) } \\
\text { (Deputy Vice Chancellors, Chief } \\
\text { Operating Officer, Deans and Associate } \\
\text { Deans of faculties) }\end{array}$ \\
\hline $\begin{array}{l}\text { Project Middle Management (PM1-8) } \\
\text { (Project team stream leaders, team } \\
\text { leaders, senior consultants, } \\
\text { Communication Manager) }\end{array}$ & $\begin{array}{l}\text { Business Administrative Group (BS1-6) } \\
\text { (Heads of Service in various business } \\
\text { areas of the university) }\end{array}$ \\
\hline $\begin{array}{l}\text { Business Analysts (BA1-8) } \\
\text { (Business Analysts in the project } \\
\text { team) }\end{array}$ & $\begin{array}{l}\text { IT Division Management Group (TM1-2) } \\
\text { (Chief Information Officer and the } \\
\text { Associate Director in IT Division of the } \\
\text { university) }\end{array}$ \\
\hline $\begin{array}{l}\text { IT Workers (TW1-5) } \\
\text { (System Programmers, System } \\
\text { Developers, System Testers in the } \\
\text { project team) }\end{array}$ & $\begin{array}{l}\text { Transition Support Group (TO1-5) } \\
\text { (Transition support staff recruited for } \\
\text { the SS implementation) }\end{array}$ \\
\hline $\begin{array}{l}\text { Training Team (TT1-2) } \\
\text { (Training Developer, Training } \\
\text { Agent) }\end{array}$ & \\
\hline
\end{tabular}

Table 1. Roles of the Participants.

Data was analysed using a grounded theory based coding paradigm developed by Strauss and Corbin (1990), which included three conceptual coding levels: open, axial and selective. Open coding includes an inductive coding process from the raw data and axial coding uses the process of relating codes to each other until themes emerge. Once themes had emerged from the data categories and sub-categories, selective coding was carried out. This final phase included taking note of the social behaviours and activities that were in the coded data set, how the coded data represented the emerged themes, and further, how the themes and the data set could answer the research questions (Strauss and Corbin 1990). In order to establish rigour and trustworthiness in the research process and therefore the findings, the current research drew upon the set of principles for evaluating interpretive field research proposed by Klein and Myers (1999) (see Appendix).

\section{Findings}

With the application of the three-phase coding strategy, two themes emerged; namely Human Relational Factors Affecting the Project and Non-Human-Relational Factors Affecting the Project (see Figure 4). The first theme is the primary focus of this research project whereas the second theme helps contextualise and understand the human relations. Under the first theme, there are two sub-themes: Project Team Relationships and Stakeholder Relationships. 


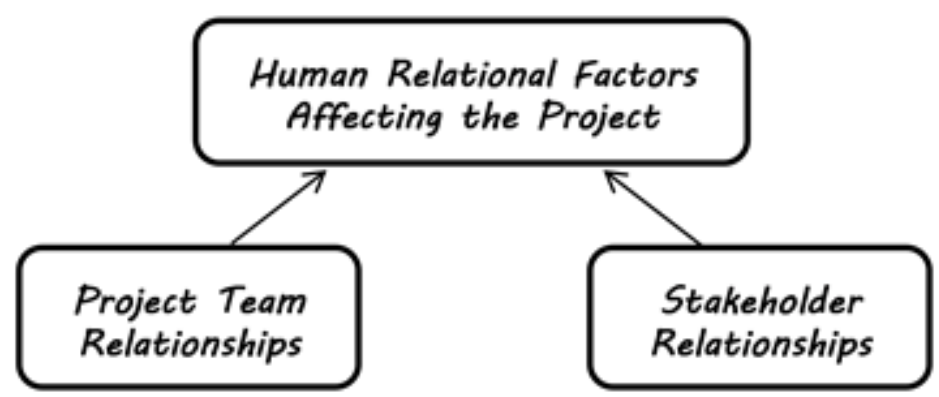

Non-Human-Relational

Factors Affecting the Project

Figure 4. Themes and Sub-Themes.

It was found that the major issues and problems that affect the implementation and institutionalisation of the IS implementation included both human relational issues and nonhuman-relational issues.

The human relational issues included:

- the intra-project-team human relational issues:

- $\quad$ ineffective project leadership,

- ineffective project team communications,

- $\quad$ negative perception of the project team culture,

- $\quad$ project team instability,

- $\quad$ project team member conflicts; and

- the project stakeholder group relational issues:

- $\quad$ negative perception of organisational culture,

- $\quad$ organisational instability,

- ineffective stakeholder communications,

- $\quad$ stakeholder conflicts.

The non-human-relational issues included

- $\quad$ inexperience of the project team and the whole university for an IT project of this size;

- $\quad$ lack of expertise in the project;

- lack of project management discipline in the project; and

- underestimation of project scope and complexity, and accordingly, the budget and timeline.

The emergence of the human relational issues reflects the importance of exploring social and power relations within IS implementation projects. The following diagram (Figure 5) graphically summarises the relationship of each of Turner's propositions to the first theme Human Relational Factors Affecting the Project, more specifically, to their relevant axial codes. The causal relationships between the axial codes and between the categories are also shown in the diagram. 


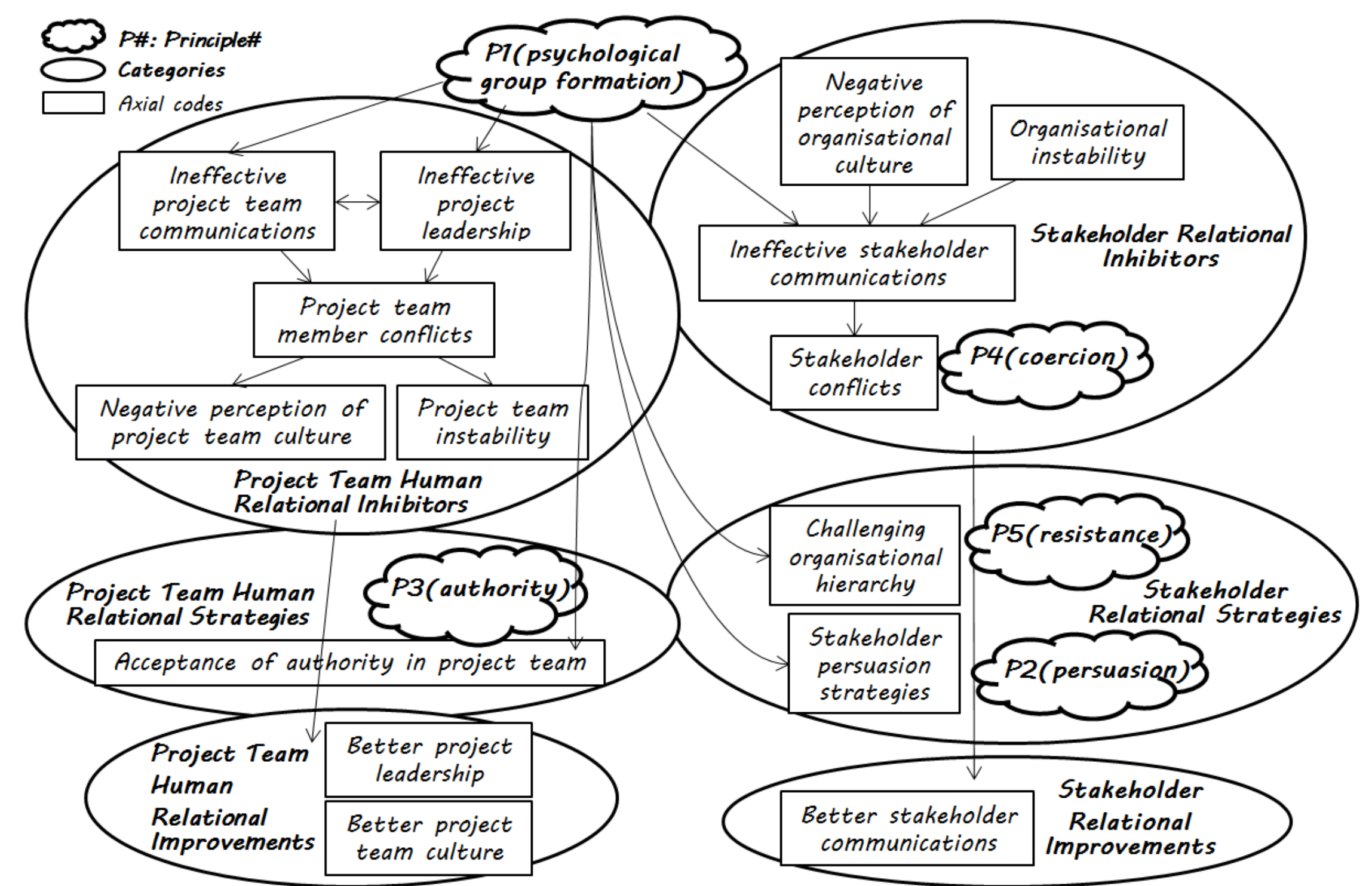

Figure 5. Relationship of TPT propositions to the Axial Codes and Categories of Human Relational Factors. 


\subsection{Project Team Human Relational Inhibitors}

Five human relational issues were identified within the SS project team. The findings suggested that ineffective project team communications and ineffective project leadership were largely driven from potential discrimination between different psychological groups. In particular, people in the SS project team tended to see two psychological groups: the business oriented people consisting mainly of Business Analysts and technically oriented people consisting mainly of System Developers and Testers. These groups consisted of persons with similar worldviews concerning the work of the project including views on the right way to do things and views on the way problems should be approached and dealt with. Although the relationships between the groups were not necessarily antagonistic, the intergroup communicative activities tended to be affected negatively by different worldviews between the groups. A Project Director described the two project staff psychological groups as follows:

"Within the rest of the team members, there is a number of, it's not formal, it's more informal, and it's all about the skill sets they have, so the business analysts can kind of be drawn together, either for 'I've got this problem I don't know how to deal with it, do you know how to, (with) one of those have you got an example you could give me' or just it's a bit of a natural 'you are at my level, so I talk to you' that pecking order stuff as well, so there is business analysts. There is (a group of) developers. This is really, you would love this: the group in that room in there, 115, we now allocate that to these testing people in there, and there is a developer in there, and I mean these are your real propeller head, techo kind of things, and they almost look alike, you never hear from them, they are all males, you know, some of them are a bit of that, you know, 1980 s long hair in a ponytail, they are centric in their clothing, one with a binni hat, he isn't even bold head, so they are just a little bit different, but you know they are developers. I've never seen them talk with anyone else other than their own group. When we sometimes have social functions, you know, on the Friday a sausage sizzle or something like that, they will be, it's almost automatic, they will go into their huddle" (a project leader, PL5, second interview, lines 126-14O).

When the issues of ineffective communication and ineffective leadership deteriorated to a point, project team member conflicts occurred. Project team member conflicts occurred that were driven from psychological group difference and discrimination. In particular, there seemed to be evident divides between the ex-business staff and externally recruited project specialists, as suggested by two project managers:

"There were, in some ways, quite evident divides between university-sourced staff on the project and contractors. That's normal for a project like this, but this one seemed to be a bit more hostile" (a project middle manager, PM8, lines 23-25).

"Within my team, I can see that I've got little cliques within my team, so people who have been here forever, you know, the old timers, and the new ones tend to stay together, and there is only a couple of people that have managed to bridge the gap. When we had the admissions and the [Student System] project, that admissions team stuck together and made decisions without even regarding anyone else in this team even though it was team of five. They were just so cliquey that you couldn't break into it, and [their team leader] encouraged that to be 'we are special, we are this...' that sort of thing" (a project middle manager, PM4, lines 468-474).

These conflicts further led to negative perception of project team culture and project team instability. The project team culture was then negatively perceived as unpleasant, political, and even 'bullying'. Moreover, frequent and considerable changes happened as a result in project staff, leadership, reporting lines, and even project team restructure.

"I think with the various examples of not so much formal complaints, but when people left with their exit interviews they either hinted at or were quite specific, and it comes in under this word that is used all the time now around 'bullying'. The word 'bullying' 
seems to, it does mean coercion I think, and it's quite commonly used now" (a project leader, PL1, second interview, lines 422-425).

"The whole, the way the structure change in the project, it was a form of bullying. (...) I was told to report to [a different Project Manager], and a month and half later, nothing was done and I just went 'no, I'm done. I'm leaving.' I'm not the only one who was leaving too, so two members were leaving at that time. The whole middle management level vanished as well. It was a very frustrating period and we just couldn't keep up with it" (a project middle manager, PM6, lines 65-68).

\subsection{Stakeholder Relational Inhibitors}

Outside the SS project team, ineffective stakeholder communications also appeared to be the result of potential discrimination between different psychological groups. The psychological group difference was likely to be more significant between stakeholder groups than between sub-groups within the project team. These ineffective communications were largely presented between the SS project team and the business stakeholder group, and reflected in the lack of senior engagement and support. A change consultant said,

"It's a game where parties didn't know how to spoil the old way of operating so that you could be successful. So the programme didn't know how to change the Executive, and the Executive didn't know how to change all the Deans, Associate Deans, and anyone else who's involved in the game making decisions, so both parties were complied in the game that couldn't succeed, so throwing a lot of money against the wall" (a project middle manager (change consultant), PM1, lines 208-212).

It was also found that the alignment with the SS project seemed to be perceived negatively by the business staff group. For example, the early project leaders were the 'accidental project managers' (Hunsberger 2011; Turner, Keegan and Crawford 2003), who were seconded from the business into the SS project. When the secondment began, there was an influential close relationship between the project and the business as the seconded project leaders maintained their influence in the university. However, when the seconded project leaders assimilated into the project and became more 'project-like', the business staff group started to feel that these seconded project leaders' influence separated the SS project and the business considerably as they made decisions in the project based on little consultation with the current business staff members. A project leader said,

"Our second issue that I would categorise has been the way, in 2010, when the project review happened and two people were seconded from the business as Director and System Director, at the time that was a very good move, it gave a lot more connection, but over time, the project and the business separated, so decisions were being made within the project that the business didn't have this ability of, so the connection and engagement wasn't so efficient." (a project leader, PL4, lines 109-113).

This finding appears to reflect that people form groups psychologically (Turner 1978), and such psychological group formation can impact on the progress of an IS implementation (Schwarz and Watson 2005).

Aside from the factor of psychological group discrimination, the stakeholder communications were also affected by negative perception of organisational culture and organisational instability. The organisational culture was perceived differently by different people, or from different points of view. Some interpreted the university as a bureaucratic environment, which led to inevitable bureaucratic inefficiency (Clegg, Harris and Hopfl 2011). The SS project staff felt hampered by too many meetings and noted a lack of efficient decision making.

"I also think it seems to be very political here and there is quite a lot of high levels of politics. There is also a lot of I guess bureaucracy or politics that happen at a high level that seem to have an impact down here, so sometimes it's [SS] meetings, and they are a lot better now, but there was a time where people were just talking about all this 
high level decision sorts of politics stuff that didn't really have any bearing on getting this done" (a Business Analyst, BA3, lines 44-49).

Others interpreted the culture of the university as too participative, and thus people could be overly flexible with changes they wanted in business processes. This made the implementation of an off-the-shelf package like SS extremely difficult as ready-made off-the-self products are not developed for specialised or individual needs.

"It's also an element of flexibility of what they can do and what they are going towards is something like locked down with rules and you have to follow what the system does, you make a change, the impact just, like, blows out. So they can't continue doing that and that's a very big cultural shift for this place particularly" (a project middle manager, $P M_{4}$, lines 451-454).

No matter which way the organisational culture was perceived, however, these negatively perceived cultural aspects constrained the progress of the SS project. Further, other organisational changes in the university and the consequent high university staff turnover also exacerbated the communications between the stakeholder groups around the SS project.

\subsection{Project Team Human Relational \& Stakeholder Relational Improvements}

The improvements of the SS project were presented differently within the project team and outside the project team. Things within the project team that were improved and then facilitated the project were the leadership and team culture, whereas outside the project team, improvements were mainly presented in stakeholder communications. It can be inferred that stakeholder communications play a critical role in determining the success of a project. The reason that the organisational culture and the organisational leadership were not among the things that were improved may be due to the fact that these two organisational factors were relatively stable and not easily changed by a single IT project.

\subsection{Project Team Human Relational Strategies}

Interestingly, the strategies that made the improvements possible and used within the project team were found to be different from those outside the project team. Acceptance of authority was the effective strategy inside the project team for managing the human relational issues. Although persuasion also emerged in the codes with respect to the intra-project-team relations, it occurred within a psychological group and acted in the way that the project staff supported their group members against the others whom they did not identify with. Thus, persuasion was not interpreted as a strategy for dealing with the intergroup issues within the project team. Instead, it appeared that the project staff tended to accept a command or a decision made by their superior in the project team. It was indicated by a number of participants that this was because they were willing to submit to the legitimate authority of their superior that was conferred by the project team hierarchy.

An example was that the first Project Director disagreed with the Project Steering Committee decision of bring in consultants for an extensive project review but obeyed it because he viewed the Steering Committee as legitimate authority he was willing to follow. He said,

"I thought it was not going to help the project in any sense. It was an enormous amount of work to bring consultants in cold. They hadn't had any previous connection with the project. (...) My initial reaction was 'this is rubbish, it's just going to distract us and all the rest of it'. However, I don't have an authority to actually stop this thing happening and therefore I've got to go along with it, and I can actually see that they've got a point in what they were asking for" (a project leader, PL1, second interview, lines 231-233; 315-318).

When the researcher continued to ask what would have been his response if this decision had been made, not by persons senior to him in the organisational hierarchy, but by someone at his own level. He replied: 
"I would have taken a much stronger argument against it certainly, yes" (a project leader, PL1, second interview, line 326).

It was inferred from the conversation that the first Project Director saw himself as belonging to the SS project staff group, and at a higher level, to the psychological group of AsiaPac university employees, and as such, he accepted the hierarchy of the project team and the organisation as legitimate and hence saw it as right that the Steering Committee could mandate an external review. He did not agree with the decision but viewed it as within the legitimate authority of the Steering Committee so that he had to obey. This supports Turner's (2005) notion of authority in the way that authority short-circuits the debates when a voluntary submission to the group norms or structure is taking place.

\subsection{Stakeholder Relational Strategies}

Outside the project team, authority power appeared to be no longer effective between the project team and the other stakeholder groups. This was due to the fact that the project leaders did not feel they had the legitimate right to order a business stakeholder to do something, especially when the project leaders came from outside the university. The business stakeholders did not see the SS project leaders as higher than themselves in the organisational hierarchy either. Many business stakeholders did not see the SS project leaders as sitting in their reporting line. Due to the lack of authority power over university business stakeholders, the SS project team eventually had to resort to persuasion strategies to manage the stakeholder relational issues. However, a direct persuasion seemed to be difficult between the SS project team and the business staff group as they did not tend to identify with each other. The project team had to rely on a number of business representatives to act as the 'change champions' for persuading their university colleagues. The persuasion between the change champions and their business people was enabled by the sharing of a 'business-stakeholder' identity and accordingly the shared belief and attitude within their psychological group. This phenomenon supports Turner's (2005) notion of persuasive power that springs from psychological group formation.

The second strategy between project stakeholders that emerged to be effective was challenging organisational hierarchy. The data suggested that, among ineffective project team communications, a critical issue was that the project team staff seconded from the university business areas were submissive to the organisational hierarchy, and thus they tended to convey better-than-real news. A project consultant said,

"I think if they come from this university, they're immediately subordinate to the traditional corporate hierarchy here rather than the project hierarchy, so they don't know how to counter or challenge, understandably, for all organisational power. If you come from other universities, as a contractor, you will be more comfortable about that. If you come from a vendor or service provider, a business like ours, then you assume you have to confront and in some ways challenge the negotiated order or the world will be as it was" (PM1, lines 454-459).

When the externally recruited project staff came on board, they challenged the organisational hierarchy when facing unrealistic mandates. In particular, the third Project Director reported the whole story to the university senior group. Her challenging the hierarchy was made possible because she and her externally recruited project specialists were less submissive to the university authority than the university-sourced project staff. The third Project Director did not see the unrealistic mandates as within the legitimate authority of the university senior group. More importantly, it was also her firm approach and her expertise and experience in managing big IT projects that made her resistance to the organisational hierarchy possible.

\subsection{Extension to the TPT}

The failure to find strong support for a social-group-identity-and-power link reflects the importance of considering other determinants of power outside the social identity approach (Tajfel and Turner 1979; Turner et al. 1987). Based on the findings discussed above, 


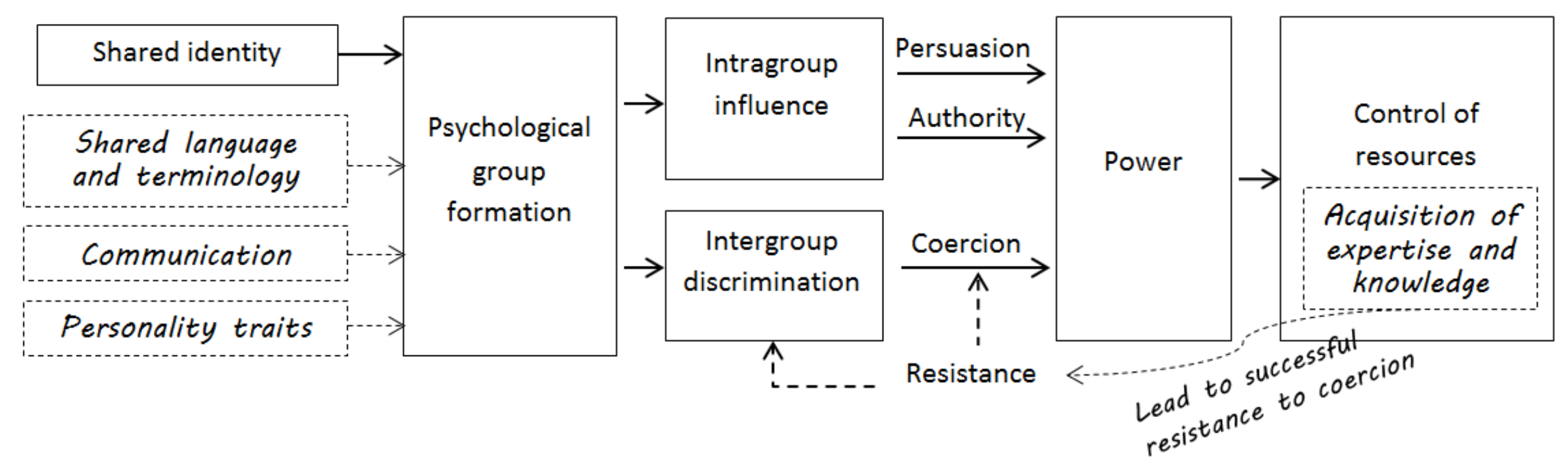

Non-Turner elements/attributes

Figure 6. Augmented Three-Process Theory of Power. 
opportunities of augmenting the TPT have been found for a more thorough understanding of the nature and the operation of power (see Figure 6 above).

As a by-product of the knowledge gained from this research, Turner's (2005) TPT is augmented by including the components marked in dotted boxes in Figure 6 . As illustrated in this diagram, the augmentations consist of two major parts: around the determinants of psychological group formation and around the power-resource causal relationship.

From our research findings, we have uncovered a number of factors that affected psychological categorisations in the SS project, which in turn affected power relational behaviours. In addition to shared social group identity, it is useful to consider alternative factors that have been found important in affecting how people identify with each other psychologically.

In line with the extant literature, it has been revealed that sharing technical language and terminology (Foucault 1977), being skilful in communication (Yukl, Falbe and Youn 1993), and/or having matched personality (Anderson and Spataro 2008) could lead to the tendency of people identifying with each other into the same psychological group. The findings also suggest that this categorisation does not need to rely on sharing work-based identity or sharing similar social background. Therefore, adding these alternative determinants of psychological group formation to Turner's theory furthers the understanding of social categorisation (Sachdev and Bourhis 1985; Tajfel et al. 1971) and the understanding of the nature of power (Simon and Oakes 2006; Turner 2005).

With regard to power and resources, Turner's TPT highlights the one-way causality of power to the creation and control of resources. The findings support Turner's argument by demonstrating that controlling resources could not necessarily lead to effective power exercise, and gaining power did lead to the creation and control of resources. However, the findings also indicate that the acquisition of expertise and knowledge were found to be the reasons that people could successfully challenge power. If one views expertise and knowledge as some form of resource, it can be argued that the control of resources could lead to power, in particular, through expert power (French and Raven 1959) or informational power (Deutsch and Gerard 1955). Thus, the acquisition of expertise and knowledge, regarded as part of resources, has been included in the construction of the augmented theory as the element that can assist the resistance to intergroup coercion. This finding adds to Turner's proposition by explaining how resistance may succeed in its expectation. That is, the acquisition of certain resources (i.e. expertise and knowledge) may lead to successful resistance to the coercion that springs from intergroup discrimination.

\section{Discussion}

Following from the above findings, this section will conclude and discuss the findings in relation to the RQs.

\section{RQ1: What power relations can be identified within an IS implementation project?}

RQ2: Does TPT provide a useful theoretical lens for understanding the interplay of power relations within an IS implementation project?

Turner's perspective $(1987 ; 2005)$ is mostly eloquent in demonstrating how social influence and power can be gained and exercised, and specifically, how social group identities affect people's categorisation of psychological groups which determines different ways of power exercises that people resort to: persuasive, authoritarian or even coercive. While Turner's TPT provides a useful theoretical lens to investigate and explain most power relational activities in the SS project, some alternative factors as determinants of power-related behaviours were discovered to be important, and as such, they need to be conceptualised and integrated into the understanding of power. Thus a more thorough understanding may be gained when Turner's theory is combined with some aspects of other relevant theories, and with some aspects related to personal characteristics and influence tactics. 
TPT has been extended by including the discovered alternative determinants of social categorisation and the potential relationship of the acquisition of resources (expertise and knowledge) to power through resistance. The alternative determinants together with the basis of social group identity, and the extended power-resource explanation, have been found to contribute to the formation of psychological groups, and to the prediction of behaviours, thereby improving the explanatory power of TPT.

\section{Conclusion}

In this paper, we aimed to explore the value of applying a social psychological perspective, namely Turner's (2005) Three-Process Theory of Power, to explain and build a deeper understanding of power related behaviours in the context of IS implementation.

\subsection{Theoretical Implications}

At a theoretical level this research has highlighted that the application of Turner's theory to the IS case study has discovered usefulness in explaining behaviours around gaining and exercising power. This research has additionally demonstrated that there were alternative sources of power and additional aspects of power-resource links affecting the IS implementation process which Turner's theoretical lens does not cover. By applying and augmenting the social psychological framework, this research has built a deeper theoretical understanding of power relations in IS implementation. This understanding was not only limited to the relations between project stakeholders; it also included the intra-project team relations.

Therefore, a major theoretical contribution of this research is the introduction of a more tangible and detailed analysis through the social identity approach (Tajfel and Turner 1979; Turner et al. 1987) for understanding and explaining the nature of power. This has been proven useful in similar research (Schwarz and Watson, 2005; van Dijk and van Dick, 2009; Tansley et al., 2013). Turner's (2005) theoretical lens formed a basis for understanding the inter- and intra-group phenomena and highlighting the thinking and action of individuals such as how the 'change champions' made possible collective products through psychological processes to facilitate the IS implementation and institutionalisation.

It is worth noting that another contribution is to Turner's TPT of Power itself. In the augmented TPT, the alternative determinants together with the extended power-resource explanation contribute to the understanding of social categorisation and power relations, and to the prediction of behaviours, thereby improving the explanatory power of Turner's theory.

\subsection{Practical Implications}

In practical terms, this research adds to knowledge concerning project management; in particular, concerning the effective management of power relations in IT projects. Based on the findings, we recommend guidelines for IT project managers or system implementers (see Table 2), on ways to persuade and to overcome political and non-political issues during IS implementation. These recommendations will provide guidance to IS theoreticians and practitioners what constitutes effective and ethical management of power relations, as well as non-human-relational aspects, in IS implementation projects. 


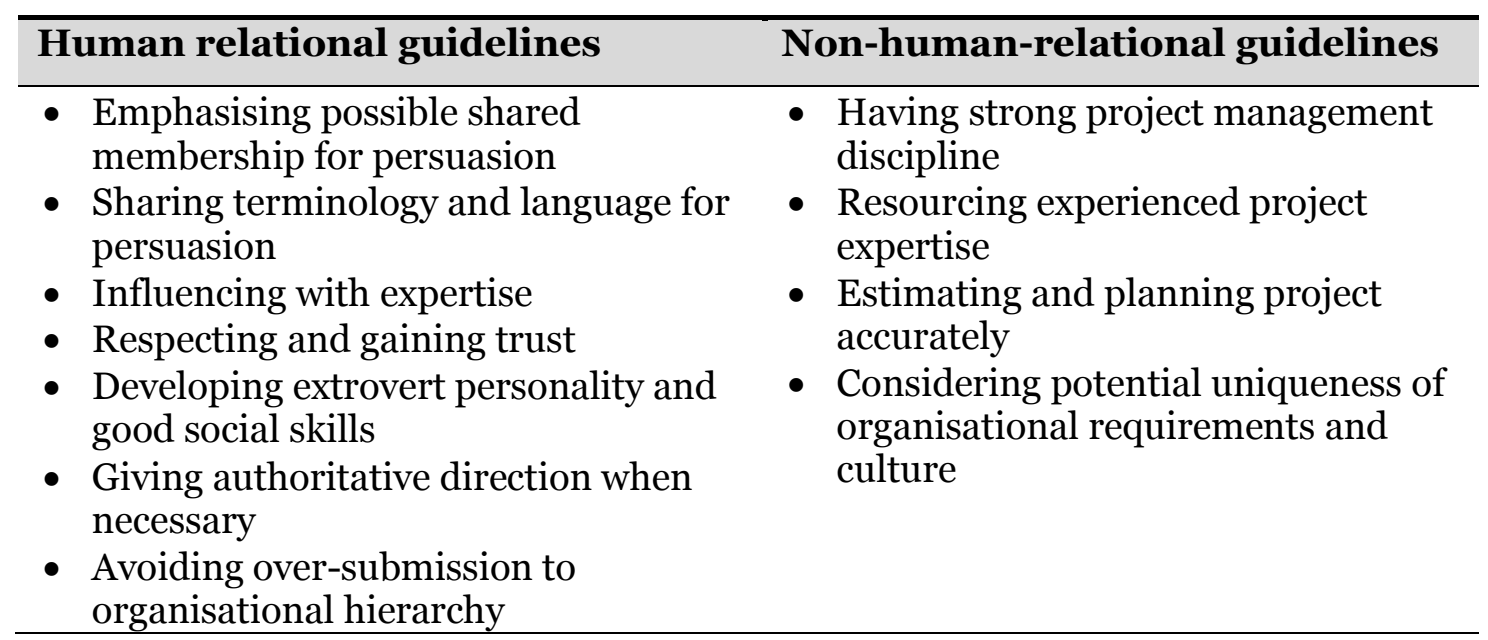

Table 2. Guidelines for IT Project Managers

\subsection{Limitations of the Study}

There are limitations within this study. First, the research was conducted in a single case study based on one higher education institution. Thus the findings could be limited by focusing on one organisation and a certain era in time. While the longitudinal data collection provided the researcher with sufficient data to produce lessons for implementing the new system at AsiaPac University, we did not provide a comparison with other higher education institutions. Insight may have been gained through such a comparison, which could be a basis for future research. Second, our assumptions based around personality traits are somewhat weak; particularly considering personality traits were not 'measured'. Nevertheless, these findings highlight the importance of further work in this area. For example, future work should aim to incorporate a survey approach to measure personality traits in order to tease out possible relationships between personality and IT project manager performance in managing project issues. A third limitation of the paper is that the case study was conducted mainly during the pre-go-live stage of the SS project and ended at the project go-live stage. This made it difficult to compare project issues and required project manager skills at different project stages. Future work could look into this aspect as different project phases often have different requirements on management skill sets.

\subsection{Future Research Directions}

There remain many possibilities for future research. It is envisaged that future research could consider a different organisational context such as non-educational organisation or private business sector. Future work could thus investigate the factors affecting IS implementation within different organisational cultures, and as such, the value of applying Turner's (2005) TPT of Power could be further explored.

As the interpretivist case study approach appears to be a useful way of exploring power issues and the value of Turner's theoretical lens, further research concerning political issues in a single organisation may benefit from adopting a similar method. Nevertheless, future research exploring power relations may find that a better understanding might be gained when a combined method is used. A combined approach for example, may enable both an in-depth understanding of the power interplays in particular political events, as well as the exploration of possible causal relationships between participants' social or work-based identities and their power behaviours (Turner 2005).

\section{References}

Anderson, C., and Spataro, S.E. 2008. "Personality and Organizational Culture as Determinants of Influence," Journal of Applied Psychology (93:3), May, pp 702-710. 
Backhouse, J., Hsu, C.W., and Silva, L. 2006. "Circuits of Power in Creating De Jure Standards: Shaping and International Information Systems Security Standard," MIS Quarterly (30:Special Issue), August, pp 413-438.

Benbasat, I., Goldstein, D.K., and Mead, M. 1987. "The Case Research Strategy in Studies of Information Systems," MIS Quarterly (11:3), September, pp 369-386.

Bloomfield, B.P., Coombs, R., Owen, J., and Taylor, P. 1997. "Doctors as Managers: Constructing Systems and Users in the National Health Service," in: Information Technology and Organizations: Strategies, Networks and Integration, B.P. Bloomfield, R. Coombs, D. Knights and D. Littler (eds.). Oxford: Oxford University Press, pp. 112134 .

Brooks, L. 1997. "Structuration Theory and New Technology: Analysing Organizationally Situated Computer-Aided Design (Cad)," Information Systems Journal (7:2), April, pp 133-151.

Chang, T.J., and Yeh, S.-P. 2014. "Intra Project Team Disagreement, Conflict Communications, and Team Performance in Cross-Functional New Product Teams: A Decision-Making Quality Perspective," South African Journal of Economic and Management Sciences (17:1), 2014, pp 91-107.

Chu, C., and Smithson, S. 2007. "E-Business and Organizational Change: A Structurational Approach," Information Systems Journal (17:4), October, pp 369-389.

Clegg, S., Harris, M., and Hopfl, H. 2011. Managing Modernity - Beyond Bureaucracy? Oxford: Oxford University Press.

Clegg, S.R. 1989. "Circuits of Power: A Framework for Analysis," in: Frameworks of Power, S.R. Clegg (ed.). London: Sage Publications, pp. 187-240.

Currie, G., Finn, R., and Martin, G. 2010. "Role Transition and the Interaction of Relational and Social Identity: New Nursing Roles in the English Nhs," Organization Studies (31:7), July 1, 2010, pp 941-961.

Dahl, R. 1957. "The Concept of Power," Behavioural Science (2:3), July, pp 201-215.

Deutsch, M., and Gerard, H.B. 1955. "A Study of Normative and Informational Social Influences Upon Individual Judgment," Journal of Abnormal \& Social Psychology (51:3), pp 629-636.

Doolin, B. 2004. "Power and Resistance in the Implementation of a Medical Management Information System," Information Systems Journal (14:4), pp 343-362.

Flowers, S. 1997. "Information Systems Failure: Identifying the Critical Failure Factors," in: Failure and Lessons Learned in Information Technology Management: An International Journal, J. Liebowitz (ed.). Elmsford, New York: Cogizant Communication Corp., pp. 19-30.

Foucault, M. 1977. Discipline and Punish: The Birth of the Prison. London: Penguin.

French, J.R.P., and Raven, B.H. 1959. "The Bases of Social Power," in: Studies in Social Power, D. Cartwright (ed.). Ann Arbor, Michigan: The University of Michigan, pp. 150-167.

Fritsche, I., Jonas, E., Ablasser, C., Beyer, M., Kuban, J., Manger, A.-M., and Schultz, M. 2013. "The Power of We: Evidence for Group-Based Control," Journal of Experimental Social Psychology (49:1), pp 19-32.

Gohler, G. 2009. "'Power to' and 'Power Over'," in: The Sage Handbook of Power, S. Clegg and M. Haugaard (eds.). London: Sage Publications.

Haslam, S.A., Ryan, M.K., Postmes, T., Spears, R., Jetten, J., and Webley, P. 2006. "Sticking to Our Guns: Social Identity as a Basis for the Maintenance of Commitment to Faltering 
Organizational Projects," Journal of Organizational Behavior (27:5), August, pp 607628.

Hogg, M.A., Martin, R., Epitropaki, O., Mankad, A., Svensson, A., and Weeden, K. 2005. "Effective Leadership in Salient Groups: Revisiting Leader-Member Exchange Theory from the Perspective of the Social Identity Theory of Leadership," Personality and Social Psychology Bulletin (31:7), July 1, 2005, pp 991-1004.

Hogg, M.A., and Turner, J.C. 1985. "Interpersonal Attraction, Social Identification and Psychological Group Formation," European Journal of Social Psychology (15:1), January, pp 51-66.

Hornsey, M.J. 2008. "Social Identity Theory and Self-Categorization Theory: A Historical Review," Social and Personality Psychology Compass (2:1), January, pp 204-222.

Hornsey, M.J., Blackwood, L., and O'Brien, A. 2005. "Speaking for Others: The Pros and Cons of Group Advocates Using Collective Language," Group Processes \& Intergroup Relations (8:3), Jul 2005, pp 245-257.

Howcroft, D., and Light, B. 2006. "Reflections on Issues of Power in Packaged Software Selection," Information Systems Journal (16:3), July, pp 215-235.

Hunsberger, K. 2011. "The Accidental Project Manager," in: PM Network. Drexel Hill: Project Management Institute, pp. 28-33.

Hussain, Z.I., and Cornelius, N. 2009. "The Use of Domination and Legitimation in Information Systems Implementation," Information Systems Journal (19:2), March, pp 197-224.

Jasperson, J., Carte, T.A., Saunders, C.S., Butler, B.S., Croes, H.J.P., and Zheng, W. 2002. "Review: Power and Information Technology Research: A Metatriangulation Review," MIS Quarterly (26:4), December, pp 397-459.

Kappelman, L.A., McKeeman, R., and Zhang, L. 2006. "Early Warning Signs of It Project Failure: The Dominant Dozen," Information Systems Management (23:4), Fall, pp 3136.

Kerr, D.V., Houghton, L., and Burgess, K. 2007. "Power Relationships That Lead to the Development of Feral Systems," Australasian Journal of Information Systems (14:2), pp 141-152.

Klein, H.K., and Myers, M.D. 1999. "A Set of Principles for Conducting and Evaluating Interpretive Field Studies in Information Systems," MIS Quarterly (23:1), pp 67-94.

Knights, D., and Vurdudakis, T. 1994. "Foucault, Power, Resistance and All That," in: Resistance and Power in Organizations, J.M. Jermier, D. Knights and W.R. Nord (eds.). London and New York: Routledge, pp. 167-198.

Kramer, R.M. 1999. "Trust and Distrust in Organizations: Emerging Perspectives, Enduring Questions," Annual Review of Psychology (50:1), February, pp 569-598.

Markus, M.L., and Bjorn-Andersen, N. 1987. "Power over Users: Its Exercise by System Professionals," Communications of the ACM (30:6), June, pp 498-504.

Mathiassen, L., and Napier, N. 2014. "Exploring Win-Win Contracts: An Appreciative Inquiry into It Project Management," Journal of Information Technology Theory and Application (14:3), pp 5-29.

Myers, M.D., and Newman, M. 2007. "The Qualitative Interview in Is Research: Examining the Craft," Information and Organization (17:1), pp 2-26.

Ngwenyama, O., and Nielsen, P.A. 2014. "Using Organizational Influence Processes to Overcome Is Implementation Barriers: Lessons from a Longitudinal Case Study of Spi 
Implementation," European Journal of Information Systems (23:2), Mar 2014, pp 205222.

Oakes, P.J., Haslam, S.A., and Turner, J.C. 1994. "Outgroup Homogeneity and Illusory Correlation Revisited," in: Stereotyping and Social Reality, P.J. Oakes, S.A. Haslam and J.C. Turner (eds.). Oxford, UK: Blackwell, pp. 160-185.

Orlikowski, W.J., and Baroudi, J.J. 1991. "Studying Information Technology in Organizations: Research Approaches and Assumptions," Information Systems Research (2:1), March, pp 1-28.

Oz, E., and Sosik, J. 200o. "Why Information Systems Projects Are Abandoned: A Leadership and Communication Theory and Exploratory Study," The Journal of Computer Information Systems (41:1), Fall, pp 66-78.

Sabherwal, R., and Grover, V. 2010. "A Taxonomy of Political Processes in Systems Development," Information Systems Journal (20:5), pp 419-447.

Sachdev, I., and Bourhis, R.Y. 1985. "Social Categorization and Power Differentials in Group Relations," European Journal of Social Psychology (15:4), pp 415-434.

Schwandt, T.A. 1994. "Constructivist, Interpretivist Approaches to Human Inquiry," in: Handbook of Qualitative Research, N.K. Dezin and Y.S. Lincoln (eds.). Thousand Oaks, CA: Sage.

Schwarz, G.M., and Watson, B.M. 2005. "The Influence of Perceptions of Social Identity on Information Technology-Enabled Change," Group \& Organization Management (30:3), June, pp 289-318.

Silva, L. 2007. "Epistemological and Theoretical Challenges for Studying Power and Politics in Information Systems," Information Systems Journal (17:2), April, pp 165-183.

Silva, L., and Backhouse, J. 2003. "The Circuits-of-Power Framework for Studying Power in Institutionalization of Information Systems," Journal of the Association for Information Systems (4:6), November, pp 294-336.

Silva, L., and Fulk, H.K. 2012. "From Disruptions to Struggles: Theorizing Power in Erp Implementation Projects," Information and Organization (22:4), October, pp 227-251.

Simon, B., and Oakes, P. 2006. "Beyond Dependence: An Identity Approach to Social Power and Domination," Human Relations (59:1), January, pp 105-139.

Smith, S., Winchester, D., Bunker, D., and Jamieson, R. 2010. "Circuits of Power: A Study of Mandated Compliance to an Information Systems Security De Jure Standard in a Government Organization," MIS Quarterly (34:3), September, pp 463-486.

Strauss, A.L., and Corbin, J. 1990. Basics of Qualitative Research: Grounded Theory Procedures and Techniques. Thousand Oaks, CA: Sage Publications.

Tajfel, H., Flament, C., Billig, M.G., and Bundy, R.F. 1971. "Social Categorization and Intergroup Behaviour," European Journal of Social Psychology (1:2), April/June, pp 149-178.

Tajfel, H., and Turner, J.C. 1979. "An Integrative Theory of Intergroup Conflict," in: The Social Psychology of Intergroup Relations, W.G. Austin and S. Worchel (eds.). Monterey, CA: Brooks/Cole, pp. 33-47.

Tansley, C., Huang, J., and Foster, C. 2013. "Identity Ambiguity and the Promises and Practices of Hybrid E-Hrm Project Teams," The Journal of Strategic Information Systems (22:3), pp 208-224.

Turner, J.C. 1978. "Social Categorization and Social Discrimination in the Minimal Group Paradigm," in: Differentiation between Social Groups: Studies in the Social Psychology of Intergroup Relations, H. Tajfel (ed.). London: Academic Press, pp. 101-140. 
Turner, J.C. 1984. "Social Identification and Psychological Group Formation," in: The Social Dimension, H. Tajfel (ed.). Cambridge: Cambridge University Press, pp. 518-538.

Turner, J.C. 1987. "A Self-Categorization Theory," in: Rediscovering the Social Group: A SelfCategorization Theory, J.C. Turner, M.A. Hogg, P.J. Oakes, S.D. Reicher and M. Wetherell, S. (eds.). Oxford, UK: Blackwell, pp. 42-67.

Turner, J.C. 1991. "The Dual-Process Model, Self-Categorization and Social Influence," in: Social Influence, J.C. Turner (ed.). Milton Keynes: Open University Press, pp. 143-173.

Turner, J.C. 2005. "Explaining the Nature of Power: A Three-Process Theory," European Journal of Social Psychology (35:1), January, pp 1-22.

Turner, J.C., Hogg, M.A., Oakes, P.J., Reicher, S.D., and Wetherell, M.S. 1987. Rediscovering the Social Group: A Self-Categorization Theory. Oxford, UK: Blackwell.

Turner, J.R., Keegan, A.E., and Crawford, L.H. 2003. "Delivering Improved Project Management Maturity through Experiential Learning," in: People in Project Management, J.R. Turner (ed.). Aldershot, UK: Gower.

van Dijk, R., and van Dick, R. 2009. "Navigating Organizational Change: Change Leaders, Employee Resistance and Work-Based Identities," Journal of Change Management (9:2), April, pp 143-163.

Ye, M., Marshall, P., McKay, J., and de Salas, K. 2014. "Power Relations in Information Systems Implementation: The Potential Contribution of Turner's Three-Process Theory of Power," in: Business Technologies in Contemporary Organizations: Adoption, Assimilation, and Institutionalization, A. Haider (ed.). Hershey, PA, USA: IGI Global.

Yukl, G., Falbe, C.M., and Youn, J.Y. 1993. "Patterns of Influence Behaviour for Managers," Group \& Organization Management (18:1), March, pp 5-28.

Copyright: (C) 2017 Ye, de Salas, Ollington \& McKay. This is an open-access article distributed under the terms of the Creative Commons Attribution-NonCommercial 3.0 Australia License, which permits non-commercial use, distribution, and reproduction in any medium, provided the original author and AJIS are credited.

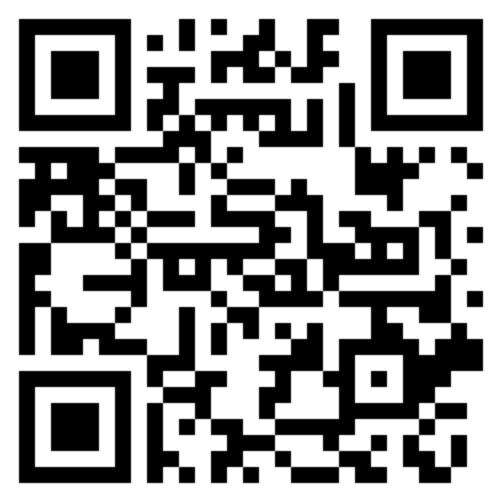




\section{Appendix}

\section{Application of Klein and Myers' Evaluation Criteria to the Case Study}

\section{Klein and Myers' criteria \\ 1 The Fundamental Principle of the Hermeneutic Circle:}

Researchers conducting case research in the hermeneutic interpretive tradition should engage in a process that all human understanding is achieved by iterating between considering the interdependent meaning of parts of that whole that they form.

\section{The Principle of Contextualisation:}

For interpretations to make sense, the researcher must account for the social and historical background of the case.

\section{The Principle of Interaction Between the Researchers and the Subjects:}

The researcher must critically reflect on how the data were socially constructed through the interaction between the researcher and participants and the participants play an active role by offering their interpretations of events.

\section{Application to the current case study}

The researcher developed an initial understanding of the power relations within the related contexts, and then revised and developed the understanding of the power-related stories by incorporating participants' feedback when appropriate. This allowed the researcher to clarify and validate the relationship between the initial theoretical framework and the data, through revising language and eliminating confusion about concepts that were emerging from the analysis.

The historical and social contexts were important in relation to the emergence of the project issues and were incorporated into the study's case narrative and analysis.

The researcher was a non-participant observer in the case study, not actively involved in the implementation project.

While the questions asked by the researcher might have introduced the participants to power and political concepts, shaping to some degree the responses they provided, the participants played an active role by offering their interpretations of events.

The researcher selected the documentary materials that would complement the data of the interview transcripts. 


\section{The Principle of Abstraction and Generalisation:}

This involves generalising particulars to abstract categories and social theories.

These general concepts describe the nature of human understanding and social action.

\section{The Principle of Dialogical Reasoning:}

This requires sensitivity to possible contradictions between the theoretical concepts employed in the study and the actual findings.
Theoretical concepts from the lens were utilised in the field work through the use of an interview guide. They were also reflected in the analysis and discussion.

The research findings provided illustrations of the theoretical concepts and the application of the theoretical framework facilitated transferring particulars to abstract concepts of social theories.

The researcher acknowledged that the participants could have had prejudices against the researcher and vice versa. Documentation analysis and observations were conducted to confirm the researcher's understanding of data throughout the data analysis process.

The researcher augmented the original conceptions of the theoretical lens by comparing and contrasting the Tumer's theoretical lens with other existing social theories during the interpretations. 